\title{
Central Retinal Artery Occlusion Associated with Atrial Septal Defect: A Case Report
}

Sharad Gupta, ${ }^{\mathrm{a}, \mathrm{e}}$ Manoj Aryal, ${ }^{\mathrm{b}, \mathrm{g}}$ Yogita Rajbhandari, ${ }^{\mathrm{a}, \mathrm{c}}$ Ajay Adhikari, ${ }^{\mathrm{d}}$ Vinit Kumar Kamble, ${ }^{\mathrm{a}, \mathrm{e}}$ Binod Aryal,, g

\begin{abstract}
:
Introduction: Central retinal artery occlusion (CRAO) is characterized by sudden obstruction of the arterial blood flow in the retinal circulation with consequent ischemic damage to the retina resulting in vision loss. An interesting case of unilateral CRAO associated with atrial septal defect (ASD) in a young female is reported here. Case: A young female presented to emergency department with history of sudden and painless loss of vision in her right eye for one day. Her visual acuity at the time of presentation was perception of light in right eye and 6/6 in left eye. On examination, anterior segments of both the eyes were normal. However, relative afferent pupillary defect was positive in her right eye. On fundus examination, right eye showed pale retina and cherry red spot whereas left eye was unremarkable. Findings were suggestive of right eye CRAO. Ocular massage was done and oral carbonic anhydrase inhibitor was given. Patient was referred to a cardiologist for further evaluation and establishment of the etiology. All tests were within reference limit except a large ASD (secundum type with left to right shunt) with a diameter of $28 \mathrm{~mm}$ was revealed on transthoracic echocardiogram. Conclusion: The association between ASD and CRAO is rare. Intracardiac shunts through defect may predispose the disease. Detailed cardiac evaluation is mandatory to rule out possible causes to prevent ocular or systemic embolic events and associated morbidity.
\end{abstract}

Keywords: Atrial Septal Defect, Central Retinal Artery Occlusion

\section{INTRODUCTION:}

Central retinal artery occlusion (CRAO) is an ophthalmic emergency and is the ocular analogue of cerebral stroke. It was first described by Von Graefes in 1859.[1] An occlusion of the central retinal artery leads to sudden painless monocular loss of vision. The etiology remains unclear in many cases. Probable causes are embolism (calcified, thrombotic, myxomatous, bacterial or cholesterol) of carotid or

Submitted: 3 March, 2019, Accepted: 21 May, 2019

Published: 25 June, 2019

a-Consultant Ophthalmologist

b-Consultant Optometrist,

c-Tilganga Institute of Ophthalmology, Kathmandu, Nepal

d-DM Resident, Department of Cardiology, National Academy of

Medical Science (NAMS), Kathmandu, Nepal

e-Sagarmatha Choudhary Eye Hospital, Siraha, Lahan, Nepal

f-Medical Laboratory Technologist

g-Kathmandu Medical College and Teaching Hospital, Kathmandu, Nepal

\section{Corresponding Author:}

Sharad Gupta, e-mail: sharadgupta00839@gmail.com

ORCID: https://orcid.org/0000-0001-8654-5172 cardiac origin, vaso-obliteration (atherosclerotic plaques, giant-cell arteritis and vasculitis) and vascular compression mainly retrobulbar mass (hematoma, neoplasms, retrobulbar injections).

Atrial septal defect (ASD) is a common congenital heart defect accounting for approximately $6-10 \%$. It causes shunting of blood between the systemic and pulmonary circulations.[2] Forty percent of patients may present with cryptogenic stroke at adulthood. Paradoxical embolism has also been reported.[3] ASD predisposes the individual to embolic events which may also involve the eye.

Here we report a unique case of unilateral CRAO associated with ASD mainly due to paradoxical embolus.

\footnotetext{
How to cite this article:
}

Gupta S, Aryal M, Rajbhandari Y, Adhikari A, Kamble VK, Aryal B. Central Retinal Artery Occlusion associated with Atrial Septal Defect: A case report. Journal of Lumbini Medical College. 2019;7(1):3 pages. DOI: https://doi.org/10.22502/jlmc.v7i1.281 Epub:2019 June 25 . 


\section{CASE REPORT:}

A 32 years female presented to the emergency department with the chief complaint of sudden and painless loss of vision in her right eye for one day. She had no significant medical and surgical history. She did not give any history of trauma or other precipitating events and was not under any regular medication. On examination, her best corrected visual acuity was perception of light (LP) and $6 / 6$ in right eye and left eye respectively. On slit lamp biomicroscopic examination, anterior segment of both eyes were normal except relative afferent pupillary defect was positive in right eye. Right fundus showed pale retina and cherry red spot whereas left fundus was found to be unremarkable on posterior segment examination (Fig.1 and Fig.2).

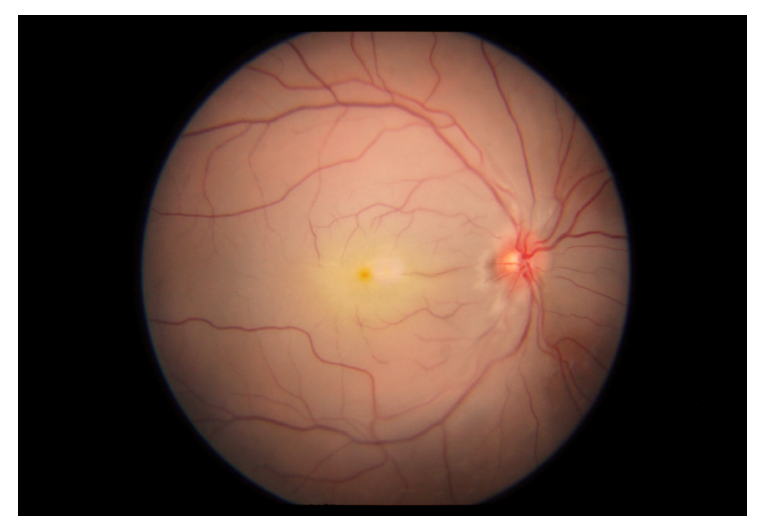

Fig. 1. Pale retina with cherry red spot on right fundus

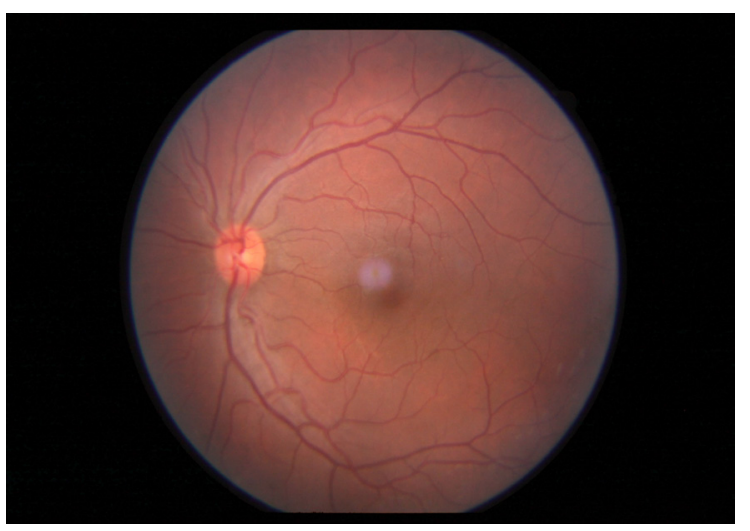

Fig. 2. Normal fundus of the left eye

Intraocular pressure were $22 \mathrm{mmHg}$ and $16 \mathrm{mmHg}$ in the right and left eyes respectively. Ocular findings were suggestive of CRAO of the right eye. Ocular massage for 15-20 minutes was done and oral carbonic anhydrase inhibitor $250 \mathrm{mg}$ four times for a day was given as for the conservative management.
Patient was referred to cardiologist to establish the etiology and for further evaluation and management of CRAO. Electrocardiogram showed right bundle branch block. Transthoracic echocardiogram revealed acyanotic congenital heart disease, large ASD (secundum type with left to right shunt) with a diameter of $28 \mathrm{~mm}$, mild tricuspid regurgitation with mild pulmonary artery hypertension and dilated right atrium and right ventricle (Fig. 3).

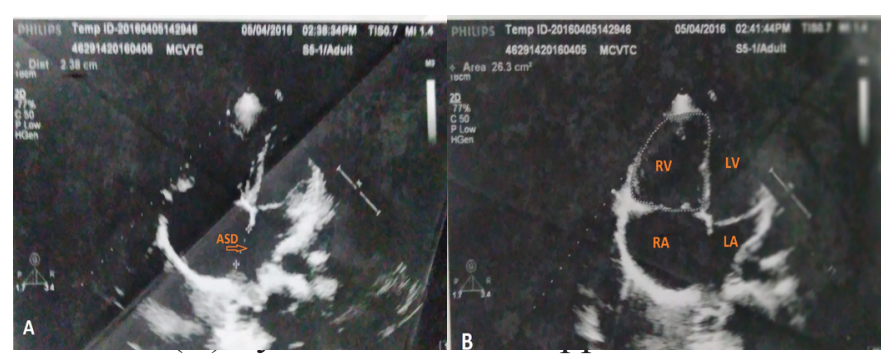

Fig. 3. Echocardiogram of the patient shows large ostium secundum ASD with left to right shunt (yellow arrow) (A), dilated right atrium and right ventricle (B) by a transthoracic approach.

Rest of the tests including carotid artery doppler, complete blood count, random blood sugar and lipid profiles were within reference limits.

\section{DISCUSSION:}

Central retinal artery occlusion (CRAO) results from the obstruction of central retinal artery; a major branch of the ophthalmic artery. CRAO is rare in patients younger than 25 years but if present, is often associated with underlying systemic or cardiac abnormality. In CRAO patients younger than 45 years, $45 \%$ have underlying cardiac abnormalities, of which $27 \%$ required anticoagulation or cardiac surgery.[4] Optic nerve head drusen and peripapillary arterial loops are the common causes of CRAO in younger patients.[5]

Association between patent foramen ovale creating a right-to-left shunting of blood with central retinal artery occlusion had been reported in various literatures.[6,7] However, direct intra-cardiac communication between venous and arterial system can also occur with atrial septal defect, pulmonary artery venous malformation, ventricular septaldefect, Ebstein anomaly and patent ductus arteriosus. These cardiac entities under various conditions like right 
arterial hypertension, right ventricular hypertension, positive pressure ventilation, positive end-expiratory pressure, pulmonary hypertension from hypoxemia, myocardial infarction of the right side of the heart and valsalva maneuvers can result into right-to-left shunt with formation of a paradoxical embolus.[8] Although there are few articles about embolic stroke in cerebellum due to paradoxical embolus across ASD [9] but CRAO associated with ASD has not been reported till date. ASD is essentially a left-to-right shunt; transient rise in right atrial pressure during Valsalva or on a ventilator could predispose the migration of air or micro-emboli in the right atrium to the arterial circulation across the ASD. $[10,11]$ In this case there might be paradoxical embolus during Valsalva maneuver (coughing, straining) which may have predisposed the migration of emboli from right atrium to systemic circulation leading to retinal artery occlusion.

\section{CONCLUSION:}

The association between ASD and CRAO is rare. Despite the fact that ASD is left to right shunt, paradoxical embolus from right atrium to systemic circulation due to transient rise in right atrium pressure can lead to embolic phenomena elsewhere in the body and sometimes in the eye. Detailed cardiac evaluation is mandatory to rule out possible causes of cardiac disease to prevent ocular or systemic embolic events and associated morbidity.

\section{Conflict of interest:}

None declared.

\section{REFERENCES:}

1. Von Graefes A. Ueber Embolie der Arteria centralis retinae als Ursache plotzlicher Erblindung. Arch Ophthalmol. 1859; 5(1):136-157. DOI: https://doi. org/10.1007/BF02720764

2. Bull C, Deanfield J, de Leval M, Stark J, Taylor JF, Macartney FJ. Correction of isolated secundum atrial septal defect in infancy. Arch Dis Child. 1981; 56 (10):784-6. PMID: 7305418

3. Rigby ML. The era of transcatheter closure of atrial septal defects. Heart. 1999; 81 (3):227-8. DOI: http://dx.doi. org/10.1136/hrt.81.3.227

4. Sharma S, Sharma SM, Cruess AF, Brown GC. Transthoracic echocardiography in young patients with acute retinal arterial obstruction. RECO Study Group. Retinal Emboli of Cardiac Origin Group. Can J Ophthalmol 1997; 32 (1):38-4. PMID:9047032

5. Newsom RS, Trew DR, Leonard TJ. Bilateral buried optic nerve drusen presenting with central retinal artery occlusion at high altitude. Eye 1995; 9(Part 6): 806-808. PMID: 8849557. DOI :https://doi.org/10.1038/ eye. 1995.202

6. T. Nakagawa, A. Hirata, N. Inoue, Y. Hashimoto, and $\mathrm{H}$. Tanihara. A case of bilateral central retinal artery obstruction with patent foramen ovale. Acta Ophthalmologica Scandinavica, 2004: 82(1); 111-112. PMID: 14738497

7. L. Clifford, R. Sievers, A. Salmon, and R. S. B. Newsom. Central retinal artery occlusion: association with patent foramen ovale. Eye, 2006; 20(6): 736-738. PMID: 6701983

8. Sunil V. Furtado, Prasanna K. Venkatesh, Ganesh K. Murthy, Arul D. Furtado, and Alangar S Hegde. Paradoxical Embolus across Atrial Septal Defect and Posterior Circulation Infarct in Neurosurgical Patients International Journal of Neuroscience. 2010; 120(7):516-520. PMID: 20583906. DOI: https://doi. org/10.3109/00207451003760072

9. Laskowski, I. A., Babu, S. C., Osinuga, Sr, O. A., Lessnau, K. D., \& Menezes, N. S. (2018, October 02). Paradoxical Embolism. Retrieved October 24, 2018, from https:// emedcine.medscape.com/article/460607-overview\#a3t

10. Fathi, A. R., Eshtehardi, P., \& Meier, B. Patent foramen ovale and neurosurgery in sitting position: A systematic review. British Journal of Anaesthesia, 2009; 102(5): 588596. . PMID: 19346525. DOI : https://doi.org/10.1093/bja/ aep063

11. Ozdemir, A. O., Tamayo, A., Munoz, C., Dias, B., \& Spence, J. D. Cryptogenic stroke and patent foramen ovale: Clinical clues to paradoxical embolism Journal of Neurological Sciences. 2008; 275(1-2): 121-127. DOI : https://doi. org/10.1016/j.jns.2008.08.018 